\title{
Decreasing wind speed and weakening latitudinal surface pressure gradients in the Tibetan Plateau
}

\author{
Qinglong You ${ }^{1,2,6}$, Shichang Kang ${ }^{1,3, *}$, Wolfgang-Albert Flügel ${ }^{2}$, Nick Pepin ${ }^{4}$, \\ Yuping Yan ${ }^{5}$, Jie Huang ${ }^{1,6}$
}

${ }^{1}$ Key Laboratory of Tibetan Environmental Change and Land Surface Process, Institute of Tibetan Plateau Research, Chinese Academy of Sciences (CAS), Beijing 100085, China

${ }^{2}$ Department of Geoinformatics, Friedrich-Schiller University Jena, Jena 07743, Germany

${ }^{3}$ State Key Laboratory of Cryospheric Science, CAS, Lanzhou 730000, China

${ }^{4}$ Department of Geography, University of Portsmouth, PO1 3HE, UK

${ }^{5}$ National Climate Center, Beijing 100081, China

${ }^{6}$ Graduate University of Chinese Academy of Sciences, Beijing 100049, China

\begin{abstract}
The Tibetan Plateau, with an average elevation of over $4000 \mathrm{~m}$ above sea level, is the highest and most extensive highland in the world. Between 1980 and 2005, the annual mean temperature has warmed at the rate of $0.38^{\circ} \mathrm{C}$ decade $^{-1}$. However, little attention has been paid to the variation of wind speed, the most important factor controlling evapotranspiration in the Tibetan Plateau. Here we used monthly mean wind speed from the Chinese Meteorological Administration data set to examine the spatial and temporal variability of wind speed at 71 stations (with elevations above $2000 \mathrm{~m}$ above sea level) in the eastern and central Tibetan Plateau during 1980-2005, and compared wind speed climatology and their trends with NCEP and ERA-40 reanalyses in the same domain. Compared with surface stations, NCEP overestimates wind speed and ERA-40 underestimates it, with mean annual biases of $0.93 \mathrm{~m} \mathrm{~s}^{-1}$ for NCEP and $-0.75 \mathrm{~m} \mathrm{~s}^{-1}$ for ERA-40. Both surface stations and NCEP reanalysis show significant decreasing trends, at rates of -0.24 and $-0.13 \mathrm{~m} \mathrm{~s}^{-1}$ decade $^{-1}$, respectively, mainly evident in spring and summer. ERA- 40 fails to capture any decrease. The above results indicate that NCEP captures wind speed better than ERA-40. We speculate that the most likely cause of diminishing wind speed are the asymmetrically decreasing latitudinal surface temperature and pressure gradients over the Tibetan Plateau, which may be part of a large-scale atmospheric circulation shift.
\end{abstract}

KEY WORDS: Tibetan Plateau $\cdot$ Wind speed $\cdot$ NCEP $\cdot$ ERA-40 $\cdot$ Pressure gradient

\section{INTRODUCTION}

The Tibetan Plateau, with an average elevation of over $4000 \mathrm{~m}$ above sea level (a.s.l.) and an area of approximately $2.5 \times 10^{6} \mathrm{~km}^{2}$, is the highest and most extensive highland in the world. It exerts profound influences not only on the local climate and environment but also on the global atmospheric circulation through its thermal and mechanical forcing (Yeh \& Gao 1979). According to the IPCC Fourth Assessment Report (IPCC 2007), global mean surface temperatures have risen by $0.74 \pm 0.18^{\circ} \mathrm{C}$ when estimated by a linear trend over the last $100 \mathrm{yr}(1906-2005)$, and the rate of warming over the last $50 \mathrm{yr}$ is almost double that over the last 100 yr. Since 1980, the annual mean temperature during 1980-2005 in the Tibetan Plateau has experienced pronounced warming, with a mean regional rate of $0.38^{\circ} \mathrm{C}$ decade $^{-1}$ (You et al. 2008a). Impacts on the local environment are profound, including an increasingly negative mass-balance of glaciers and increasing permafrost temperature. The active layer, i.e. the top layer of soil that thaws during summer and freezes again during autumn, has thickened (Zhang et al. 2007).

Long-term change has been examined in many parts of the climate system in the Tibetan Plateau, including mean temperature (Liu \& Chen 2000), mean precipitation (Niu et al. 2004), extreme temperature and precip- 
itation (You et al. 2008a), future warming (under the Special Report on Emissions Scenario [SRES] A1B scenario), and the influence of surface water vapor on warming (Rangwala et al. 2009, 2010). The average annual evapotranspiration in the Tibetan Plateau ranges from about 600 to $700 \mathrm{~mm}$, with a decreasing rate of $13.1 \mathrm{~mm} \mathrm{decade}^{-1}$ during 1961-2001, which is thought to be linked to a general decrease in intensity of the regional monsoon circulation. This appears to be in contrast to a predicted increased hydrological cycle under global warming scenarios (Chen et al. 2006). Wind speed, the leading factor controlling evapotranspiration in the Tibetan Plateau (Chen et al. 2006, Zhang et al. 2007), has not been subject to as much detailed examination, although previous studies (Niu et al. 2004, Chen et al. 2006, Zhang et al. 2007) show a decreasing trend in wind speed, consistent with observations in eastern China (Xu et al. 2006, Li et al. 2008).

The aim of the present study was to analyze the variation of wind speed and its temporal trends in the Tibetan Plateau and to identify connections with spatial patterns of temperature changes in the region. We examined observational surface data from the National Climate Center, China Meteorological Administration (CMA), and compared this with output from the National Center for Environmental Prediction/National Center for Atmospheric Research (NCEP/NCAR) Re- analysis (NCEP hereafter) (Kalnay et al. 1996) and the European Centre for Medium-Range Weather Forecasts (ECMWF) reanalysis (ERA-40 hereafter) (Uppala et al. 2005).

\section{DATA SETS AND METHODS}

Monthly mean wind speeds at 71 stations, distributed in the eastern and central Tibetan Plateau, were provided by the CMA. Stations were selected (Fig. 1) from the data sets according to selection procedures described in You et al. (2008a,b, 2010). Elevations are all $>2000 \mathrm{~m}$ a.s.l., and the distribution of station elevations is shown in Fig. 2. At the beginning of the 1970s, observational measurement of wind speed was changed and therefore a marked discontinuity of data records exists at this time (Xu et al. 2006). To avoid this problem, we selected data from 1980-2005. Our data comes from the EL-type measurement which records wind speed every $10 \mathrm{~min}$. The daily mean wind speed was calculated as the mean of all the daily records at a height of 10 to $12 \mathrm{~m}$, and the monthly mean wind speed was calculated as the mean of the daily records for a given month.

Monthly mean wind speed NCEP reanalysis data were provided by the NOAA Earth System Research

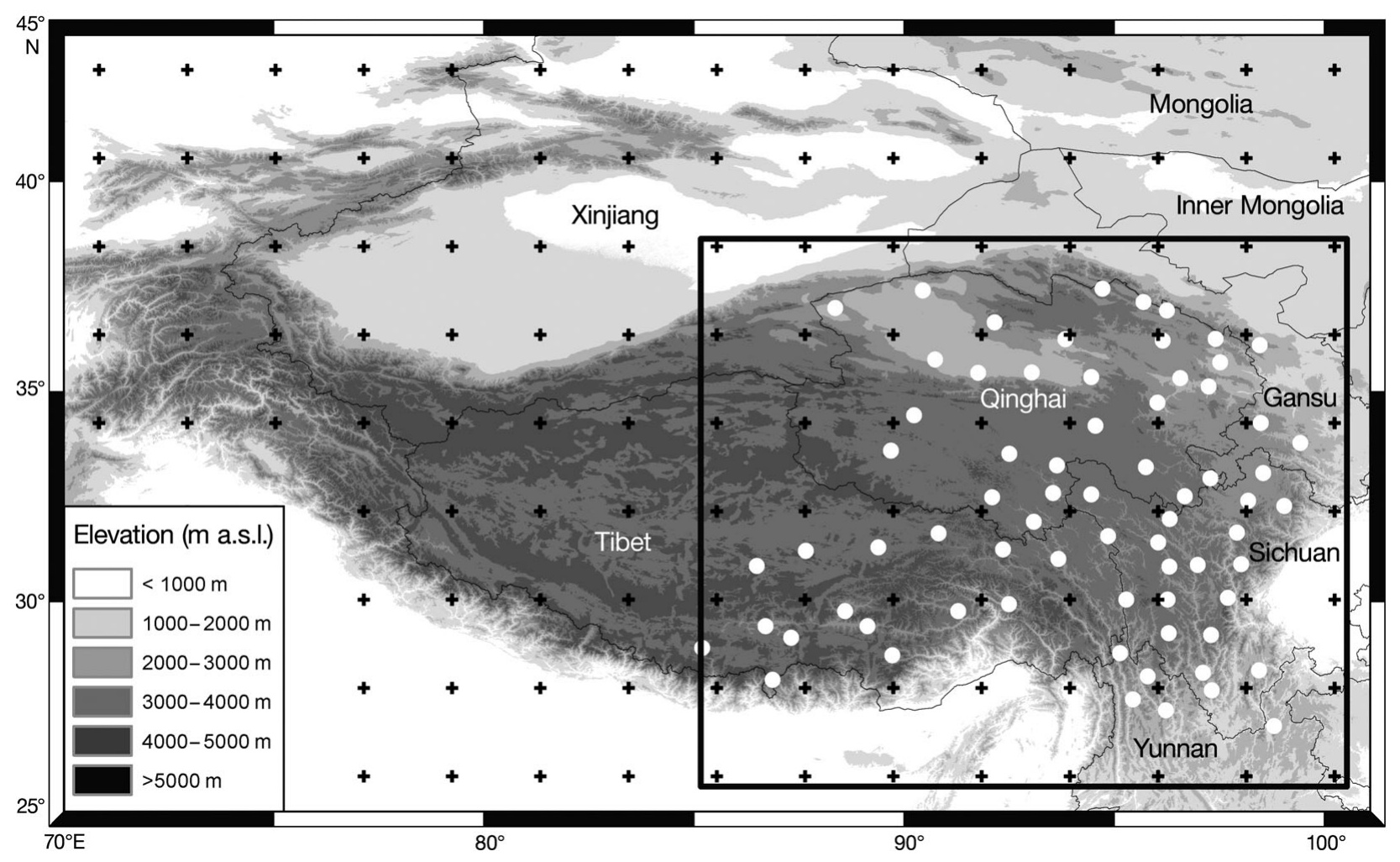

Fig. 1. Distribution of 71 surface stations (dots) and 56 NCEP/ERA-40 reanalysis grid points (crosses in rectangle) in the eastern and central Tibetan Plateau. a.s.l.: above sea level 


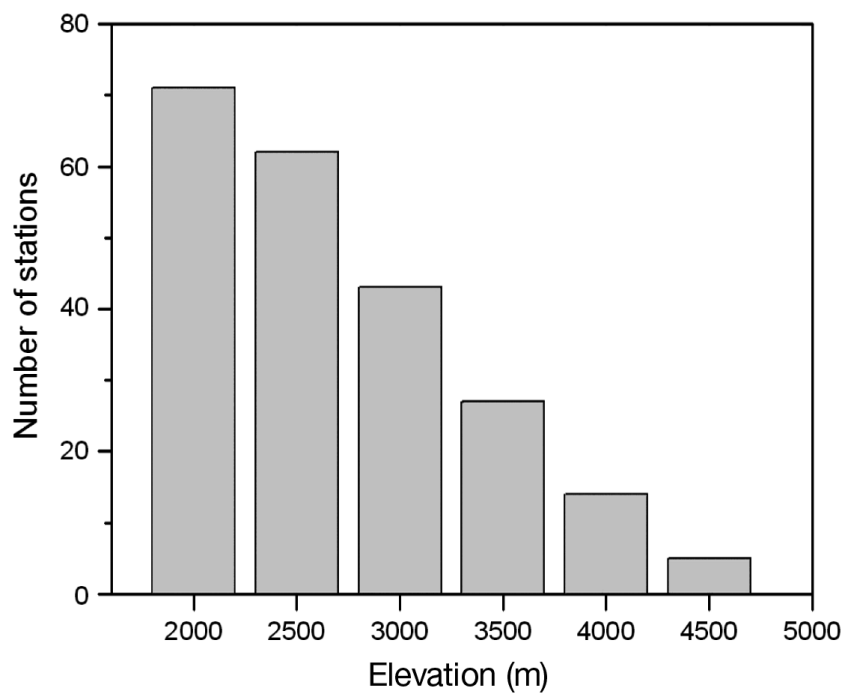

Fig. 2. Number of selected stations above the categorized elevation in the eastern and central Tibetan Plateau
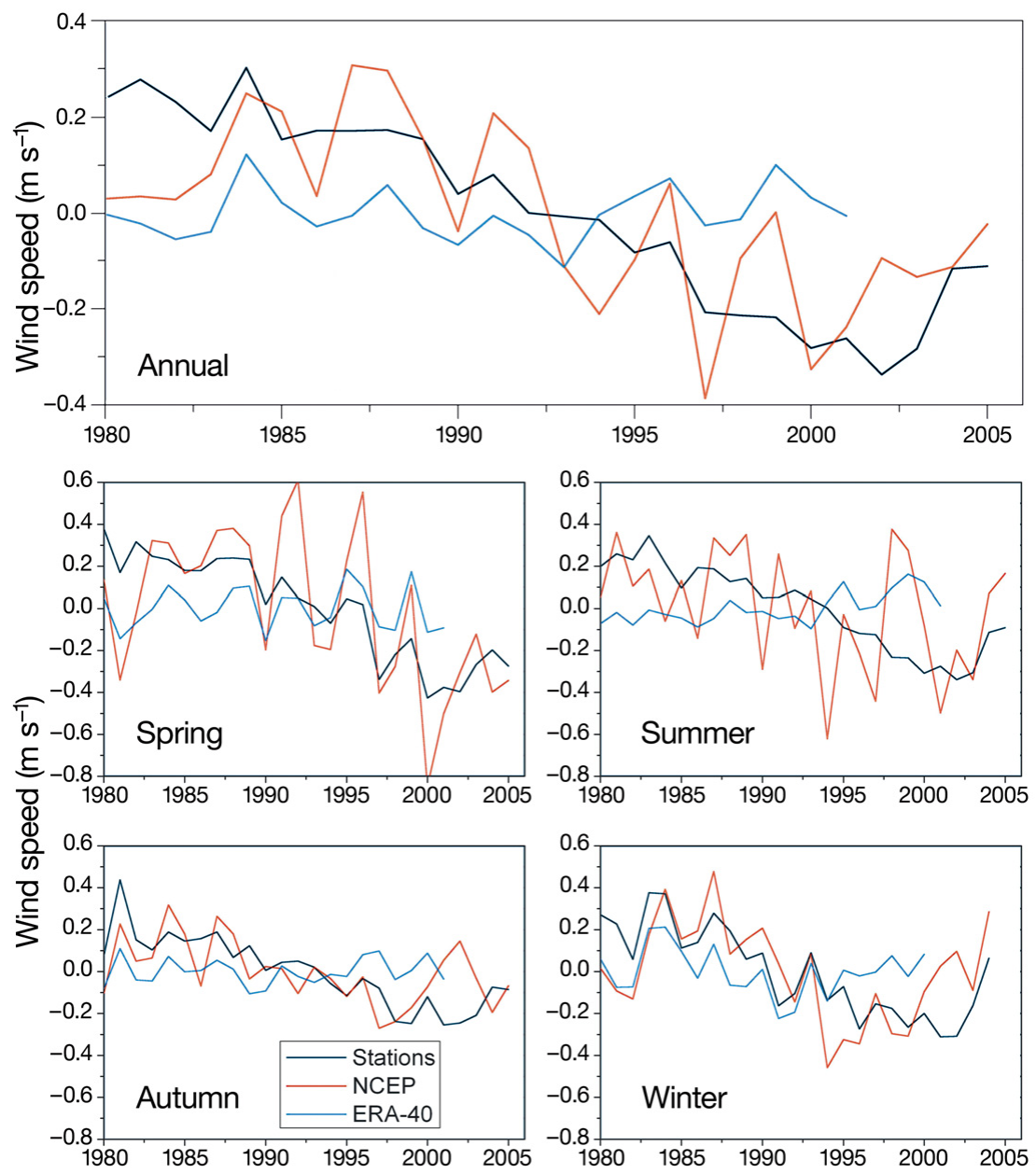

Fig. 3. Regional annual and seasonal anomalies of surface wind speed for surface stations, NCEP and ERA-40 reanalysis grid points in the eastern and central Tibetan Plateau. Study periods for stations, NCEP and ERA-40 are 1980-2005, 1980-2005 and 1980-2001, respectively
Laboratory, Physical Sciences Division (www.cdc. noaa.gov/). Although this data covers January 1948 to the present with a spatial resolution of $2.5^{\circ} \times 2.5^{\circ}$ (Kalnay et al. 1996), we selected data from $1980-2005$ only. The monthly mean wind speed ERA-40 reanalysis data were obtained from the ECMWF (www. ecmwf.int/). ERA-40 data sets are available from September 1957 to August 2002 with a spatial resolution of $2.5^{\circ} \times 2.5^{\circ}$ (Uppala et al. 2005); we selected data from 1980-2001. The slightly shorter period for ERA40 , due to lack of more current data, has limited influence on our results (data not shown). To compare with surface stations, we selected grid points contained within the rectangle outlined in Fig. 1, thus covering the same spatial domain as the surface stations. There are 56 grid points corresponding to the surface stations. We attempted to calculate regional average trends to amalgamate stations or grid points by combining unweighted locations.

The Mann-Kendall test (widely used for detecting trends in climatic research) and Sen's slope estimates were used to detect and estimate trends in annual and seasonal wind-speed series (Sen 1968). A trend was considered to be statistically significant at the $5 \%$ level.

\section{RESULTS}

\subsection{Trends of wind speed at surface stations during 1980-2005}

Fig. 3 shows the mean annual and seasonal time series of wind speed at surface stations in the eastern and central Tibetan Plateau during 1980-2005. The annual and seasonal mean trends along with the number of stations with increase/decrease trends in wind speed in the region are described in Table 1. On an annual basis, the mean Tibetan Plateau wind speed series exhibits a statistically significant decreasing trend at a rate of $-0.24 \mathrm{~m} \mathrm{~s}^{-1}$ decade $^{-1}$, with all but one of the stations showing a significant increase. Stations having the largest trend magnitudes are situated on the western Tibetan Plateau (data not shown), which is consistent with the highest wind speed. At a seasonal level, the highest rate of decrease was observed in spring $\left(-0.29 \mathrm{~m} \mathrm{~s}^{-1}\right.$ decade $\left.^{-1}\right)$ and the trend is significant. As was the case for annual means, most stations 
Table 1. Annual and seasonal mean trends of wind speed $\left(\mathrm{m} \mathrm{s}^{-1}\right.$ decade $\left.^{-1}\right)$ at surface stations, NCEP and ERA-40 reanalysis grid points in the eastern and central Tibetan Plateau. The number of stations or grid points with increasing/decreasing trends are also shown. The trends and number of stations with a significance level $>95 \%$ are highlighted in bold and shown in parentheses, respectively. The study periods for surface stations, NCEP and ERA-40 are 1980-2005, 1980-2005 and 1980-2001, respectively

\begin{tabular}{|lccccc|}
\hline & Annual & Spring & Summer & Autumn & Winter \\
\hline Stations & & & & & \\
1980-2005 & $\mathbf{- 0 . 2 4}$ & $\mathbf{- 0 . 2 9}$ & $\mathbf{- 0 . 2 4}$ & $\mathbf{- 0 . 1 9}$ & $\mathbf{- 0 . 2 3}$ \\
Increase & $9(1)$ & $8(2)$ & $5(2)$ & $8(2)$ & $8(1)$ \\
Decrease & $62(56)$ & $63(50)$ & $62(54)$ & $62(44)$ & $61(41)$ \\
NCEP & & & & & \\
1980-2005 & $\mathbf{- 0 . 1 3}$ & $\mathbf{- 0 . 2 2}$ & -0.12 & $\mathbf{- 0 . 1 0}$ & -0.11 \\
Increase & $18(3)$ & $14(1)$ & $22(4)$ & $27(1)$ & $25(6)$ \\
Decrease & $38(23)$ & $42(17)$ & $34(16)$ & $29(10)$ & $31(13)$ \\
ERA-40 & & & & & \\
1980-2001 & 0.01 & -0.01 & $\mathbf{0 . 0 6}$ & 0.02 & -0.02 \\
Increase & $29(16)$ & $28(11)$ & $35(17)$ & $31(7)$ & $26(6)$ \\
Decrease & $27(14)$ & $28(10)$ & $21(6)$ & $25(8)$ & $30(11)$ \\
\hline
\end{tabular}

(50) showed a statistically significant decrease. Rates for summer, autumn and winter were $-0.24,-0.19$ and $-0.23 \mathrm{~m} \mathrm{~s}^{-1}$ decade $^{-1}$, respectively, and at least $86 \%$ of stations showed decreasing trends in all seasons.

To investigate whether topography influences the wind speed in the region, we categorized each station into 3 topographic types - summit, flat and valleyaccording to a topographical index derived from GTOPO30 digital elevation data (available from http:// eros.usgs.gov). We calculated a topographical index by overlaying a grid centered on each station and calculated the elevation difference between the station and the 8 surrounding cells (8 directions: N, NE, E, SE, S, SW, W and NW) (You et al. 2008b). These 8 values were summed to get the topographical index; the higher the index the more sheltered or valley-like the site. The mean trend magnitudes of wind speed in the differing topographical classes are shown in Table 2. Summit stations had the largest trend magnitudes on an annual and seasonal basis, and valley stations had larger trend magnitudes than flat stations in most cases, suggesting that topographic effect may influ-

Table 2. Number of stations and trend magnitudes in wind speed in differing topographical classes in the eastern and central Tibetan Plateau on an annual and seasonal basis. Units are $\mathrm{m} \mathrm{s}^{-1}$ decade $^{-1}$

\begin{tabular}{|lcccccc|}
\hline Station & No. stations & Annual & Spring & Summer & Autumn & Winter \\
\hline Summit & 6 & -0.32 & -0.39 & -0.33 & -0.24 & -0.30 \\
Flat & 32 & -0.23 & -0.27 & -0.22 & -0.17 & -0.24 \\
Valley & 33 & -0.24 & -0.29 & -0.25 & -0.19 & -0.22 \\
\hline
\end{tabular}
wind speeds at individual surface stations compared with equivalent wind speed estimates from the nearest NCEP and ERA-40 reanalysis grid points. The mean differences between the surface stations and reanalysis grid point wind speeds are shown in Table 3.

At the annual scale, NCEP reanalysis data is fairly well correlated with the surface stations $(R=0.72, p<$ 0.0001). There are also stronger correlations for the 4 seasons. This is remarkably high, given the variable differences in topography and elevation between surface station and grid point locations. However, NCEP consistently overestimated wind speed when compared to the surface stations on both an annual and seasonal basis. This is probably because the surface stations are preferentially sited in sheltered valley bottom locations. The 

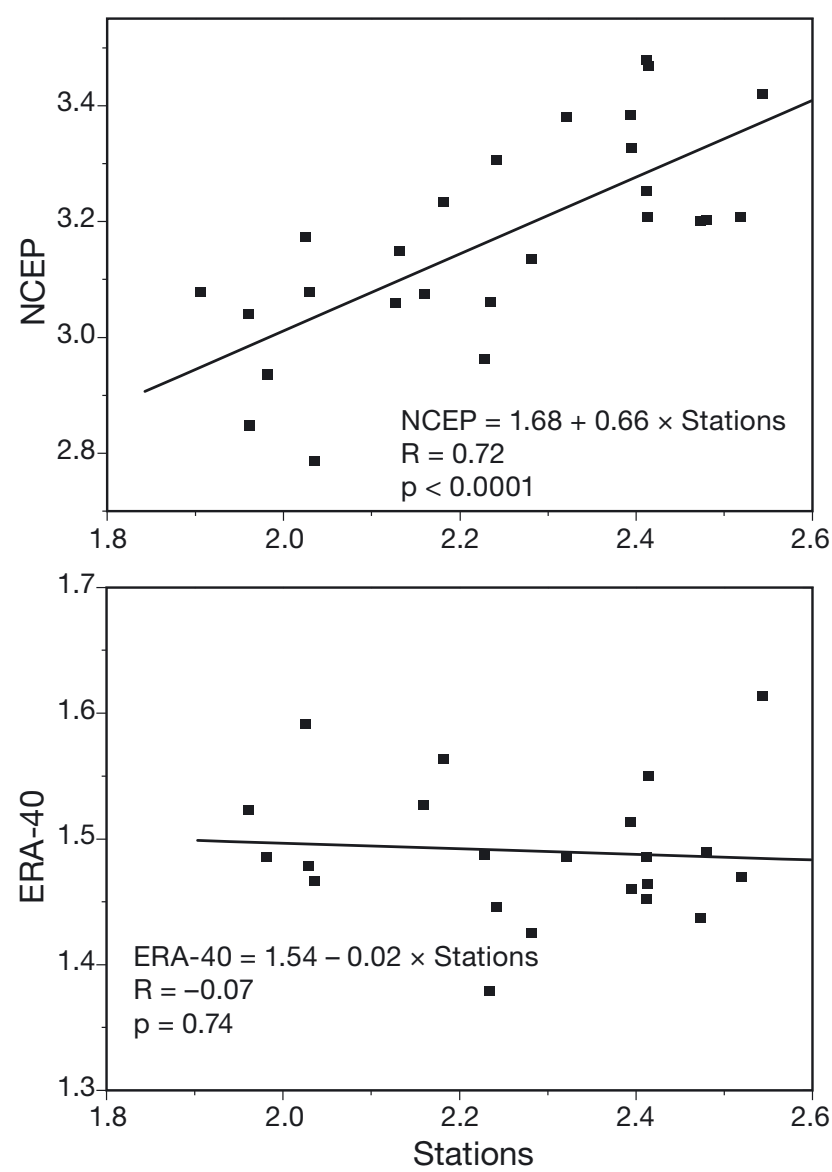

Fig. 4. Relationships between annual mean wind speed $\left(\mathrm{m} \mathrm{s}^{-1}\right)$ at 71 surface stations and the annual mean wind speed extracted from NCEP and ERA-40 on an annual basis. The straight lines are linear fits

mean overestimation is $0.93 \mathrm{~m} \mathrm{~s}^{-1}$ on the annual time scale, with a smaller difference in spring $\left(0.44 \mathrm{~m} \mathrm{~s}^{-1}\right)$ but a larger difference in winter (1.76 $\mathrm{m} \mathrm{s}^{-1}$; Table 3). The correlation between ERA-40 annual mean wind speed and that at the surface stations was weak $(\mathrm{R}=$ -0.07 ), and the weak correlations also occurred for all 4 seasons. Unlike NCEP, ERA-40 underestimated mean wind speed compared with surface values. The mean difference in annual wind speed was $0.75 \mathrm{~m} \mathrm{~s}^{-1}$. The largest and smallest biases occurred in spring and winter, with values of 1.08 and $0.60 \mathrm{~m} \mathrm{~s}^{-1}$, respectively (Table 3).

To summarize, the decreasing trend in surface station wind speed was on average stronger than in both reanalyses (Fig. 3). However, compared with ERA-40, NCEP showed much higher interannual consistency with the surface observations, indicating that NCEP better captured the past interannual variability of observed wind speed. Furthermore NCEP was also much more similar to the surface stations in terms of quantifying decreasing trends.
Table 3. Annual and seasonal mean wind speeds $\left(\mathrm{m} \mathrm{s}^{-1}\right)$ at surface stations, NCEP and ERA-40 reanalysis grid points in the eastern and central Tibetan Plateau. The differences between surface stations and reanalyses are also shown. The study periods for surface stations, NCEP and ERA-40 are 1980-2005, 1980-2005 and 1980-2001, respectively

\begin{tabular}{|lrrrrr|}
\hline & Annual & Spring & Summer & Autumn & Winter \\
\hline Stations & 2.24 & 2.77 & 2.10 & 1.90 & 2.18 \\
NCEP & 3.17 & 3.21 & 2.90 & 2.63 & 3.95 \\
ERA-40 & 1.49 & 1.69 & 1.41 & 1.27 & 1.58 \\
Stations-NCEP & -0.93 & -0.44 & -0.80 & -0.73 & -1.76 \\
Stations-ERA-40 & 0.75 & 1.08 & 0.68 & 0.63 & 0.60 \\
\hline
\end{tabular}

\section{DISCUSSION AND CONCLUSIONS}

Although reanalyses and surface stations do not always agree in detail, there is a pronounced tendency for a weakening of mean wind speeds to be observed at the surface of the Tibetan Plateau since 1980. This is especially strong in the surface observations. The global surface warming is more pronounced over high latitudes than over low latitudes from both climate projections and observations (IPCC 2007). Wind speed, especially at high elevations which are dominated by the thermal wind relation, is related to the surface pressure gradient, which in turn is a function of the surface temperature gradient (Klink 1999). In a previous study in the Tibetan Plateau (You et al. 2010), we also found that wind speed was negatively correlated with surface air temperature during the studied period based on an annual and seasonal basis (data not shown). To examine the evidence for a weakening latitudinal temperature gradient, we defined 3 regions for the Tibetan Plateau ( $85^{\circ}$ to $105^{\circ} \mathrm{E}$ ): low latitude (LL; $20^{\circ}$ to $\left.25^{\circ} \mathrm{N}\right)$, middle latitude $\left(\mathrm{ML}^{\circ} 35^{\circ}\right.$ to $\left.40^{\circ} \mathrm{N}\right)$ and high latitude $\left(\mathrm{HL} ; 50^{\circ}\right.$ to $\left.55^{\circ} \mathrm{N}\right)$. We then calculated the surface temperature and pressure gradients between the 3 regions using monthly surface temperature and pressure data derived from the NCEP reanalysis (Kalnay et al. 1996). Warming rates over the 1980-2005 period showed significant increases at $0.26,0.29$ and $0.46^{\circ} \mathrm{C}$ decade $^{-1}$, respectively for the 3 latitudinal bands, with increased warming at higher latitudes (Fig. 5). This asymmetric warming will reduce latitudinal temperature contrasts. Long-term decreases were also demonstrated in the mean annual surface pressure gradient between LL and ML and between ML and HL (Fig. 6). Although surface pressures at all latitudes are increasing, the increase appears strongest at higher latitudes. The weakening pressure gradient between high and low latitudes in the Tibetan Plateau sector may be an important contributor to the decreasing trend in wind speed. We also know little about future changes in 

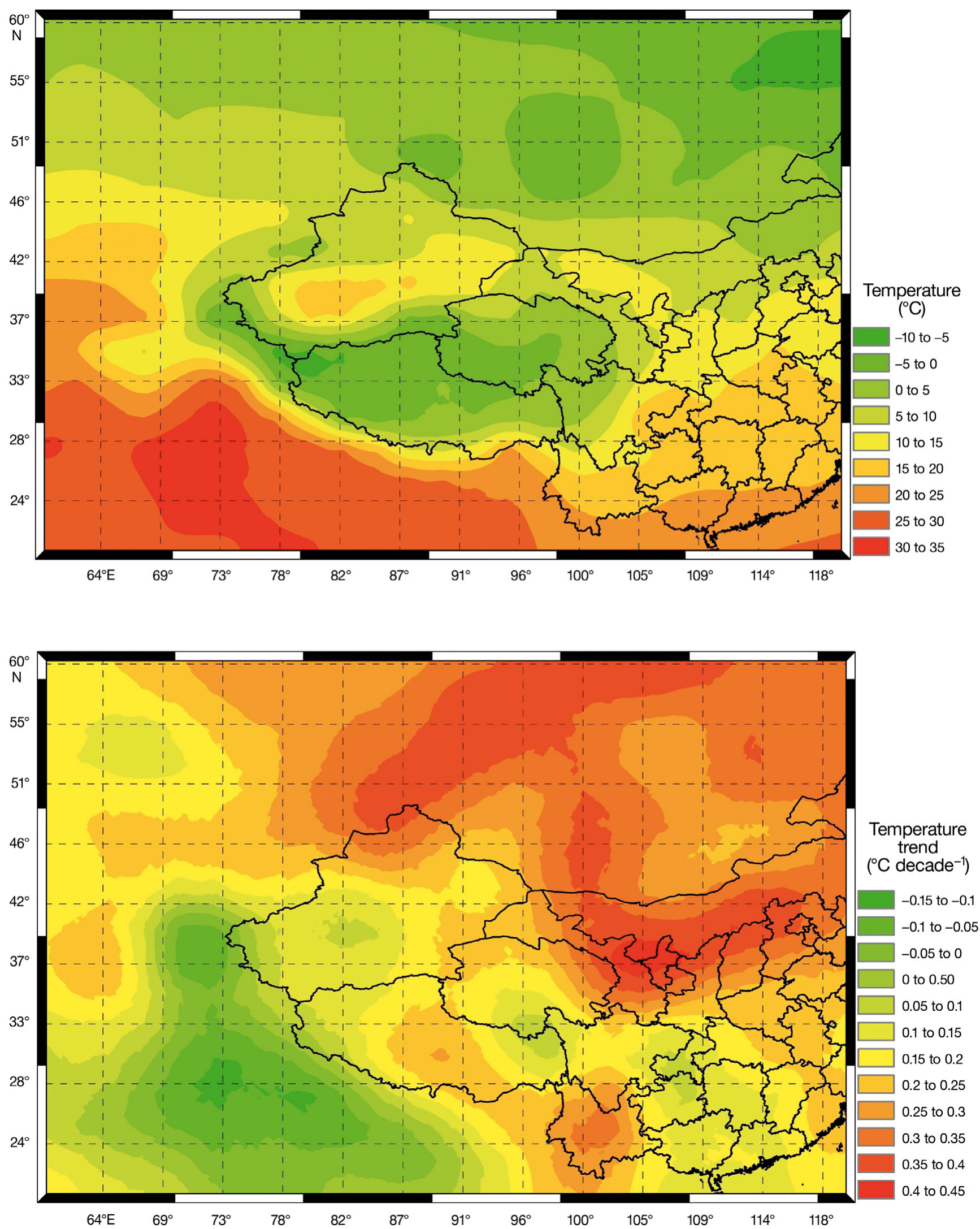

Fig. 5. Spatial distribution of annual mean temperature (top) and temperature trend magnitudes (bottom) during 1980-2005 
wind speed over the Tibetan Plateau because projections differ from the observed trends. Therefore, more attention should be paid to the future variability of wind speed in the Tibetan Plateau. For example, recent scenarios for wind speeds across Europe suggest relatively modest changes $( \pm 10 \%$ in the mean), even by the second half of the 21st century (Pryor et al. 2006, Michelangeli et al. 2009). Furthermore, projected changes are comparable to the variation in scenarios downscaled from different climate models, and are seldom distinguishable from baseline (1961-1990) variability until the second half of the 21st century (Pryor et al. 2005).

Our findings are consistent with other changes in the climate system reported over the Tibetan Plateau. Sensible heat flux in the Tibetan Plateau has shown a significant decreasing trend since the mid-1980s (Duan \& Wu 2008), with surface humidity also increasing (Rangwala et al. 2009), which would also decrease latent heat flux (evapotranspiration). Reduced fluxes will suppress turbulent transport and adiabatic lapse rates near the surface, weaken the surface cyclonic circulation and reduce wind speed locally. Additionally, the surface sensible heat flux in the Tibetan Plateau generates a strong influx of monsoonal airflow. Recent studies have reported that the Indian summer monsoon has been weakened and is becoming more unreliable and erratic (Wu 2005, Dash et al. 2009).

In addition to changes at synoptic scales (such as cyclone activity and the development of the Indian monsoon), surface changes at small scales (e.g. urbanization, changes in land cover, air pollution) can also affect surface wind speed (Klink 1999, 2002). The Arctic Oscillation (AO) and North Atlantic Oscillation (NAO) are

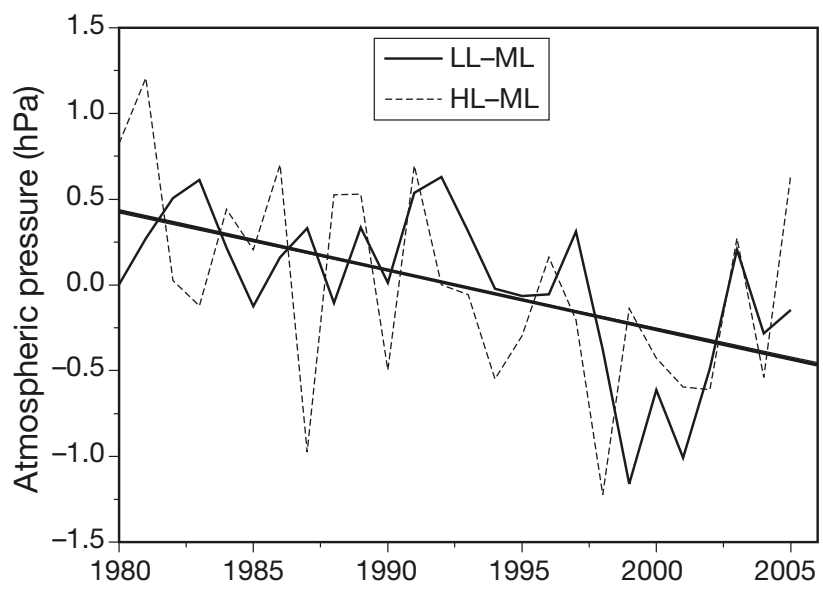

Fig. 6. The anomaly of latitudinal surface pressure gradients between low, mid and high latitudes in the Tibetan Plateau sector during 1980-2005 (based on NCEP mean annual surface pressure data). We defined 3 regions for the Tibetan Plateau $\left(85^{\circ}\right.$ to $105^{\circ} \mathrm{E}$ ): low latitude (LL; $20^{\circ}$ to $25^{\circ} \mathrm{N}$ ), middle latitude (ML; $35^{\circ}$ to $40^{\circ} \mathrm{N}$ ) and high latitude (HL; $50^{\circ}$ to $55^{\circ} \mathrm{N}$ ) the dominant patterns of Northern Hemisphere climate variability, which are most prevalent in winter and in the mid-high latitudes. Both the AO and NAO indices have increasing/decreasing trends before/after 1990, which are inconsistent with the decreasing trend after the 1980s (Fig. 7). The influence of AO and NAO on atmospheric circulation, particularly the westerlies, might influence wind speed in the Tibetan Plateau. So far, most effects have been seen in other parts of China. Li et al. (2008) suggest that urbanization, forest destruction and agriculture irrigation have contributed to the observed weakened mean wind speed and the downward near-surface wind power in China during 1960-1999. Local cooling over south-central China, probably resulting from air pollution, has been suggested to be the cause of decreased wind speeds in summer in that area (Xu et al. 2006). Although some land use change and industrialization has occurred in the Tibetan Plateau (Frauenfeld et al. 2005), direct anthropogenic impact is relatively small. To what extent such small-scale influences are important in ex-
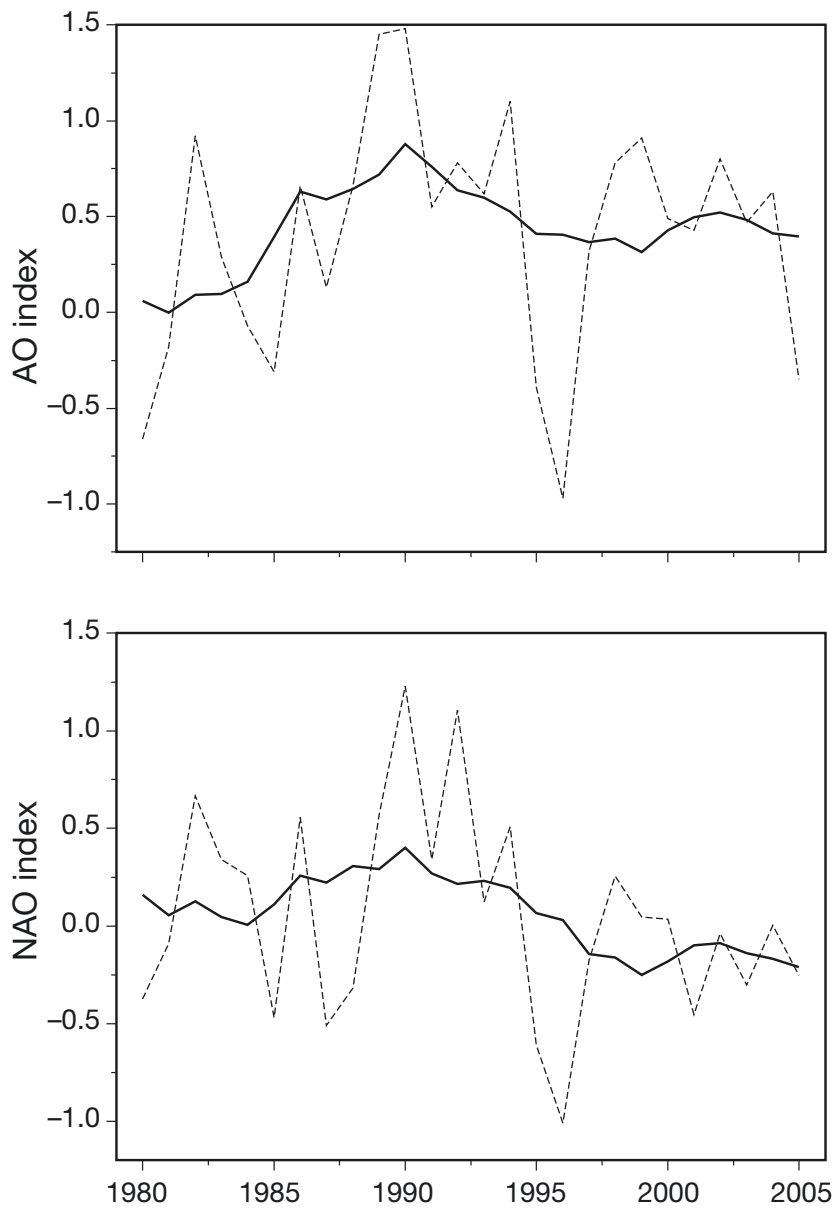

Fig. 7. Annual anomalies of Arctic Oscillation (AO) and North Atlantic Oscillation (NAO) indices during the 1980-2005 period. The smoother curve is the $9 \mathrm{yr}$ smoothing average 
plaining the wind speed decline reported in the Tibetan Plateau is unknown, and requires further study.

Finally, the lack of agreement between ERA-40, in particular, and changes observed in the surface stations is a cause for concern, and a subject for further research. This is not unique to the Tibetan Plateau. In Australia, reanalysis systems also did not capture the stilling phenomenon in wind speed (McVicar et al. 2008). A high resolution of daily wind speed grids was developed by interpolating measurements, which can represent the magnitude and spatial variability of observed wind speed trends (McVicar et al. 2008). This suggested that their methodology can also be used to develop wind speed grids in the Tibetan Plateau. More attention should be given to all reanalysis systems when using them to represent past, present or future surface wind speeds for research.

Acknowledgements. This study is supported by the National Natural Science Foundation of China $(40870743$, 40771187), the National Basic Research Program of China (2005CB 422004), the Sixth Framework Programme Priority (036952), the Chinese Academy of Sciences (KZCX2-YW-145) and the European Commission (212921). The authors thank the National Climate Center, China Meteorological Administration, for providing wind speed data. Q.Y. is supported by the DAAD-CAS Joint Scholarship Program and funded by the CAS Special Grant for Postgraduate Research, Innovation and Practice. We are very grateful to the 4 anonymous reviewers for their constructive comments and thoughtful suggestions.

\section{LITERATURE CITED}

> Chen SB, Liu YF, Axel T (2006) Climatic change on the Tibetan Plateau: Potential evapotranspiration trends from 1961-2000. Clim Change 76:291-319, doi:10.1029/2008 DO10572

Dash SK, Kulkarni MA, Mohanty UC, Prasad K (2009) Changes in the characteristics of rain events in India. J Geophys Res 114:D10109, doi:10.1029/2008/D010572

Duan AM, Wu GX (2008) Weakening trend in the atmospheric heat source over the Tibetan plateau during recent decades. I. Observations. J Clim 21:3149-3164

Frauenfeld OW, Zhang TJ, Serreze MC (2005) Climate change and variability using European Centre for Medium-Range Weather Forecasts reanalysis (ERA-40) temperatures on the Tibetan Plateau. J Geophys Res 110:D02101, doi:10. 1029/2004JD005230

IPCC (2007) Summary for policymakers. In: Solomon SD, Qin M, Manning M, Chen Z, Marquis M, Averyt KB, Tignow M, Miller HL (eds) Climate change 2007: the physical science basis. Contribution of Working Group I to the Fourth Assessment Report of the Intergovernmental Panel on Climate Change. Cambridge University Press, Cambridge

Kalnay E, Kanamitsu M, Kistler R, Collins W and others (1996) The NCEP/NCAR 40-year reanalysis project. Bull Am Meteorol Soc 77:437-471

Klink K (1999) Trends in mean monthly maximum and minimum surface wind speeds in the coterminous United States, 1961 to 1990. Clim Res 13:193-205

Klink K (2002) Trends and interannual variability of wind

Editorial responsibility: Helmut Mayer,

Freiburg, Germany speed distributions in Minnesota. J Clim 15:3311-3317

Li Y, Wang Y, Chu HY, Tang JP (2008) The climate influence of anthropogenic land-use changes on near-surface wind energy potential in China. Chin Sci Bull 53:2859-2866

Liu XD, Chen BD (2000) Climatic warming in the Tibetan Plateau during recent decades. Int J Climatol 20:1729-1742

McVicar TR, VanNiel TG, Li LT, Roderick ML, Rayner DP, Ricciardulli L, Donohue RJ (2008) Wind speed climatology and trends for Australia, 1975-2006: capturing the stilling phenomenon and comparison with near-surface reanalysis output. Geophys Res Lett 35:L20403, doi:10.1029/2008 GL035627

Michelangeli PA, Vrac M, Loukos H (2009) Probabilistic downscaling approaches: Application to wind cumulative distribution functions. Geophys Res Lett 36:L11708, doi:10.1029/ 2009GL038401

Niu T, Chen LX, Zhou ZJ (2004) The characteristics of climate change over the Tibetan Plateau in the last 40 years and the detection of climatic jumps. Adv Atmos Sci 21:193-203

> Pryor SC, Schoof JT, Barthelmie RJ (2005) Climate change impacts on wind speeds and wind energy density in northern Europe: empirical downscaling of multiple AOGCMs. Clim Res 29:183-198

Pryor SC, Schoof T, Barthelmie RJ (2006) Winds of change? Projections of near-surface winds under climate change scenarios. Geophys Res Lett 33:L11702, doi:10.1029/2006 GL026000

Rangwala I, Miller J, Russell G, Xu M (2010) Using a global climate model to evaluate the influences of water vapor, snow cover and atmospheric aerosol on warming in the Tibetan Plateau during the twenty-first century. Clim Dyn 34:859-872

Rangwala I, Miller JR, Xu M (2009) Warming in the Tibetan Plateau: possible influences of the changes in surface water vapor. Geophys Res Lett 36:L06703, doi:10.1029/ 2009GL037245

> Sen PK (1968) Estimates of regression coefficient based on Kendall's tau. J Am Stat Assoc 63:1379-1389

- Uppala SM, Kållberg PW, Simmons AJ, Andrae U and others (2005) The ERA-40 re-analysis. Q J R Meteorol Soc 131: 2961-3012

Wu BY (2005) Weakening of Indian summer monsoon in recent decades. Adv Atmos Sci 22:21-29

Xu M, Chang CP, Fu CB, Qi Y, Robock A, Robinson D, Zhang HM (2006) Steady decline of east Asian monsoon winds, 1969-2000: evidence from direct ground measurements of wind speed. J Geophys Res 111:D24111, doi:10.10129/ 2006JD007337

Yeh TC, Gao YX (1979) Meteorology of the Qinghai-Xizang (Tibet) Plateau. Science Press, Beijing (in Chinese)

You QL, Kang SC, Aguilar E, Yan YP (2008a) Changes in daily climate extremes in the eastern and central Tibetan Plateau during 1961-2005. J Geophys Res 113:D07101, doi:10.10129/2007JD009389

You QL, Kang SC, Pepin N, Yan YP (2008b) Relationship between trends in temperature extremes and elevation in the eastern and central Tibetan Plateau, 1961-2005. Geophys Res Lett 35:L04704, doi:10.10129/2007GL032669

You QL, Kang SC, Pepin N (2010) Relationship between temperature trend magnitude, elevation and mean temperature in the Tibetan Plateau from homogenized surface stations and reanalysis data. Global Planet Change 71: $124-133$

Zhang YQ, Liu CM, Tang YH, Yang YH (2007) Trends in pan evaporation and reference and actual evapotranspiration across the Tibetan Plateau. J Geophys Res 112:D11210, doi:10.10129/2006JD008161 